\title{
Provincial and temporal variation in macrolide and lincosamide antimicrobial use by outpatients in Canada, 1995 to 2010
}

\author{
Shiona K Glass-Kaastra PhD ${ }^{1}$, Rita Finley MSc ${ }^{1}$, Jim Hutchinson MD FRCPC ${ }^{2}$, David M Patrick MD FRCPC MHSc $\mathrm{C}^{3,4}$, \\ Karl Weiss MD MSc FRCPC 5 , John Conly MD FRCPC FACP6,7,8
}

SK Glass-Kaastra, R Finley, J Hutchinson, DM Patrick, K Weiss, J Conly. Provincial and temporal variation in macrolide and lincosamide antimicrobial use by outpatients in Canada, 1995 to 2010. Can J Infect Dis Med Microbiol 2014;25(2):103106.

INTRODUCTION: Because antimicrobial use is commonly associated with the development of antimicrobial resistance, monitoring the volume and patterns of use of these agents is very important.

OBJECTIVE: To assess the use of macrolide and lincosamide (ML) antimicrobials within Canadian provinces over time, and to compare use rates with those reported by European countries.

METHODS: Antimicrobial prescribing data were used to develop two yearly metrics: prescriptions per 1000 inhabitant-days (PrIDs) and the mean defined daily doses (DDDs) per prescription, which were then used to build linear mixed models to assess differences among provinces over time.

RESULTS: After accounting for repeated measures over time, prescribing rates (PrIDs) varied significantly according to province and year $(\mathrm{P}<0.001)$. However, little change occurred within each province over the time frame studied; from 1995 to 2010, each province had a PrID change $<0.01$. Quebec and British Columbia had significantly lower prescribing rates than all other provinces. No overall secular trend was apparent. In contrast, the DDDs per prescription did not vary significantly according to province, but showed a significant yearto-year increase.

DISCUSSION: ML prescribing varied among provinces in Canada between 1995 and 2010, but remained relatively stable within each province. The average DDDs per ML prescription did not vary according to province, but increased linearly over time. These increases are likely to indicate that fewer prescriptions are being written for children over time, a practice supported by good antimicrobial stewardship principles.

Key Words: Antimicrobial use; Macrolides; Prescribing practices; Provincial variation; Surveillance

$\mathrm{C}$ ontinued surveillance of antimicrobial prescription rates and volumes is necessary to target specific locations and antimicrobials for interventions to reduce use. Previous reports have determined that antimicrobial use varies among the drug classes and among the provinces in Canada (1). Therefore, it is important to assess each class of antimicrobials individually and at the provincial level. The objective of the present work was to document trends in use of the macrolide and lincosamide (ML) antimicrobial class at the provincial level, as

\section{La variation provinciale et temporelle}

d'utilisation de l'antimicrobien lincosamide en consultations externes au Canada entre 1995 et 2010

INTRODUCTION : Puisque l'utilisation d'antimicrobiens s'associe souvent à l'apparition d'une résistance aux antimicrobiens, il est très important d'en surveiller le volume et les profils d'utilisation OBJECTIF : Évaluer l'utilisation des antimicrobiens marcolides et lincasomides (ML) dans les provinces canadiennes au fil du temps et comparer les taux d'utilisation par rapport à ceux des pays européens. MÉTHODOLOGIE : Les données de prescription d'antimicrobiens ont permis d'établir deux mesures annuelles : les prescriptions par 1000 habitants-jours (PrID) et les doses quotidiennes définies (DQD) moyennes par prescription, qui ont ensuite été utilisées pour créer des modèles linéaires mixtes d'évaluation des différences entre les provinces au fil du temps.

RÉSULTATS : Après avoir tenu compte des mesures répétées au fil du temps, les taux de prescription (PrID) variaient de manière significative selon la province et l'année $(\mathrm{P}<0,001)$. Cependant, on a observé peu de changements dans chaque province pendant la période de l'étude. En effet, de 1995 à 2010, chaque province présentait un changement des PrID de moins de 0,01. Le Québec et la ColombieBritannique présentaient un taux de prescription considérablement plus faible que toutes les autres provinces. Aucune tendance lourde globale n'était apparente. Par contre, les DQD par prescription ne variaient pas de manière significative selon la province, mais augmentait de manière significative d'une année à l'autre.

EXPOSÉ : Les prescriptions de ML étaient variables entre les provinces du Canada de 1995 à 2010, mais demeuraient relativement stables dans chaque province. Les DQD moyennes par prescription de ML ne variaient pas selon la province, mais présentaient une augmentation linéaire au fil du temps. Ces augmentations sont susceptibles d'indiquer que moins de prescriptions sont rédigées pour les enfants au fil du temps, une pratique soutenue par de bons principes de gouvernance antimicrobienne.

well as to examine trends in the use of the seven individual drugs within the class. Trends in the prescribing rates were assessed using a population-adjusted measure (prescriptions per 1000 inhabitant-days [PrIDs]), while the volume of active ingredient per prescription was described using the defined daily doses (DDDs) per prescription measure.

The use of standardized population-adjusted measures of antimicrobial use, including PrIDs, DDDs per 1000 inhabitant-days

${ }^{1}$ Public Health Agency of Canada, Centre for Food-borne, Environmental and Zoonotic Infectious Diseases, Guelph, Ontario; ${ }^{2}$ Division of Medical Microbiology, Island Medical Program; ${ }^{3}$ British Columbia Centre for Disease Control; ${ }^{4}$ School of Population and Public Health, University of British Columbia, Vancouver, British Columbia; ${ }^{5}$ Department of Infectious Diseases and Microbiology, University of Montreal, Hôpital Maisonneuve-Rosemont, Montreal, Quebec; ${ }^{6}$ Department of Medicine; ${ }^{7}$ Department of Microbiology, Immunology and Infectious Diseases; ${ }^{8}$ Department of Pathology and Laboratory Medicine, University of Calgary, Calgary, Alberta

Correspondence: Ms Rita Finley, Public Health Agency of Canada, Centre for Food-borne, Environmental and Zoonotic Infectious Diseases, 255 Woodlawn Road, Unit 120, Guelph, Ontario N1H 8J1. Telephone 519-826-2213, fax 519-826-2244, e-mail rita.finley@phac-aspc.gc.ca 


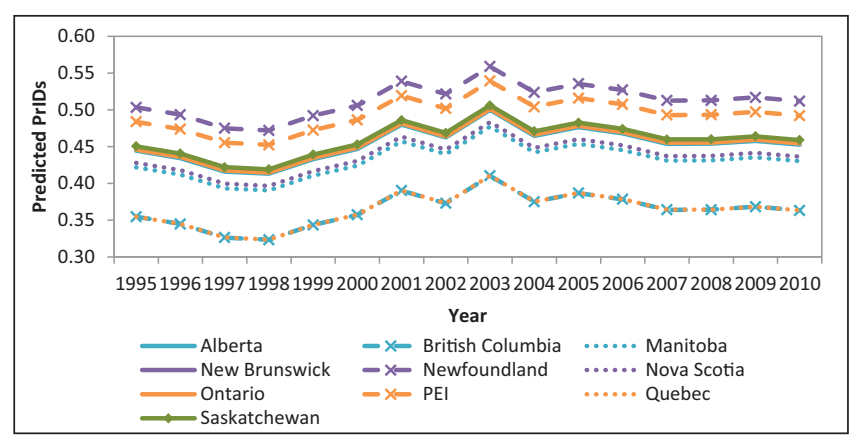

Figure 1) Linear mixed model predicted values for provincial trends in macrolide and lincosamide antimicrobial prescriptions per 1000 inhabitantdays (PrIDs), 1995 to 2010. PEI Prince Edward Island

TABLE 1

$P$ values for the difference in model predictions among Canadian provinces for the linear mixed model describing provincial differences in macrolide and lincosamide prescriptions per 1000 inhabitant-days, 1995 to 2010

\begin{tabular}{llllllllll}
\hline & BC & MB & NB & NF & NS & ON & PE & QC & SK \\
\hline AB & 0.010 & ns & ns & ns & ns & ns & ns & 0.011 & $\mathrm{~ns}$ \\
BC & - & ns & 0.007 & $<0.001$ & 0.036 & 0.009 & $<0.001$ & $\mathrm{~ns}$ & 0.006 \\
$\mathrm{MB}$ & - & - & $\mathrm{ns}$ & 0.019 & $\mathrm{~ns}$ & $\mathrm{~ns}$ & $\mathrm{~ns}$ & $\mathrm{~ns}$ & $\mathrm{~ns}$ \\
$\mathrm{NB}$ & - & - & - & $\mathrm{ns}$ & $\mathrm{ns}$ & $\mathrm{ns}$ & $\mathrm{ns}$ & 0.007 & $\mathrm{~ns}$ \\
$\mathrm{NF}$ & - & - & - & - & 0.030 & $\mathrm{~ns}$ & $\mathrm{~ns}$ & $<0.001 \mathrm{~ns}$ \\
$\mathrm{NS}$ & - & - & - & - & - & $\mathrm{ns}$ & $\mathrm{ns}$ & 0.036 & $\mathrm{~ns}$ \\
$\mathrm{ON}$ & - & - & - & - & - & - & $\mathrm{ns}$ & 0.009 & $\mathrm{~ns}$ \\
$\mathrm{PE}$ & - & - & - & - & - & - & - & $<0.001 \mathrm{~ns}$ \\
$\mathrm{QC}$ & - & - & - & - & - & - & - & - & 0.006
\end{tabular}

$\overline{A \text { significant } P \text { value indicates that a significant difference in prescribing exists }}$ between the provinces. AB Alberta; BC British Columbia; MB Manitoba; NF Newfoundland and Labrador; ns No significant difference between the provincial estimates; NS Nova Scotia; ON Ontario; PE Prince Edward Island; QC Quebec; SK Saskatchewan

(DIDs) and DDDs per prescription, also allowed for the comparison of antimicrobial use among countries. Data from 2009 were used to compare antimicrobial use in Canadian provinces with data reported from the European Surveillance of Antimicrobial Resistance Network (ESAC-Net) to determine where Canada ranked among other reporting countries in terms of ML use (2,3).

\section{METHODS}

The number of prescriptions dispensed to outpatients in each Canadian province was collected by IMS Health Canada, and acquired by the Public Health Agency of Canada's Canadian Integrated Program for Antimicrobial Resistance and the former Canadian Committee for Antimicrobial Resistance (4). The Canadian CompuScript dataset is developed by accessing all marketed outpatient drug data dispensed via prescriptions by 5900 geographically representative retail pharmacies across Canada, with provincial-level coverage ranging from $51 \%$ to $88 \%$. Geospatial extrapolation is used to infer use across all 8800 pharmacies (current as of May 2013). The extrapolation stratifies according to pharmacy size, type and province (5). This methodology nullifies any variance in store coverage over time and across geography. All data were reported monthly according to province for all new and refilled prescriptions. The Canadian CompuScript dataset included individual drug-level prescription count information, but also included manufacturer name, extended units prescribed (total number of tablets, capsules, millilitres, etc), drug strength, volume of active ingredient and patient acquisition cost. Monthly prescription counts at the provincial level were obtained for 1995 to 2010 for all azithromycin, clarithromycin and erythromycin products dispensed, and for 2000 to 2010 for the

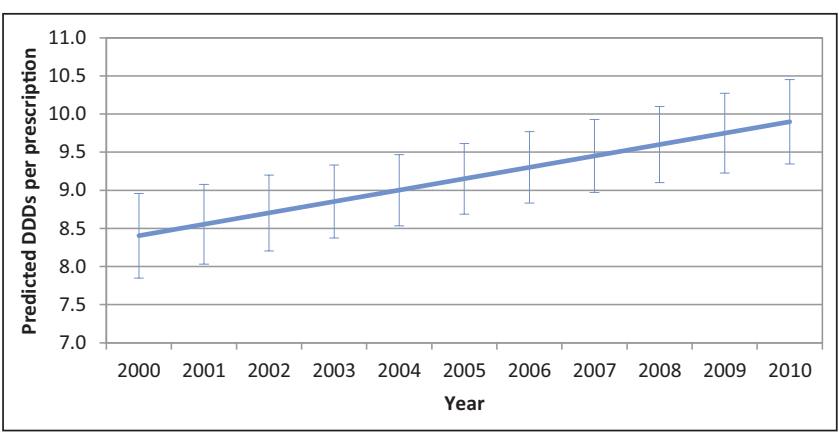

Figure 2) Linear mixed model predicted values and 95\% CIs for the defined daily doses (DDDs) per prescription for macrolide and lincosamide antimicrobials dispensed in Canada, 2000 to 2010

remaining ML products (clindamycin, lincomycin, spiramycin and telithromycin). The prescription counts were combined with population data from Statistics Canada to develop two populationstandardized measures (PrIDs and DIDs) (6). The volume of active ingredient, number of extended units dispensed and strength of the product were also acquired for all observations during the 2000 to 2010 time period. These additional data allowed for the development of the DID and DDD per prescription measures. Data from Newfoundland and Labrador and Prince Edward Island were combined for the years 1999 to 2004. In 2005 and subsequent years, data from these provinces were provided individually.

Linear mixed models were built in a forward step-wise fashion to assess differences in use according to province over the 1995 to 2010 study frame, and to describe provincial differences in the PrIDs and DDDs per prescription over time. Province and year were assessed as predictors for use at $\mathrm{P}<0.05$ and assessed for confounding effects using a $25 \%$ change cut-off in any significant coefficient. Quadratic terms for year were assessed at $\mathrm{P}<0.05$ where visually appropriate to model a curvilinear relationship between time and the outcome, as well as interaction terms between province and year, and province with the quadratic term for year. Population values were acquired from Statistics Canada (6). First-order autoregressive correlation structures were applied to both models to account for repeated measures over time, and both models met the assumptions of normality and homoscedasticity by consensus of normality tests at $\mathrm{P}<0.05$ and visual assessment of the residuals, respectively. Year was modelled as a categorical variable in the PrID model to account for a nonlinear relationship with the outcome, while the linear structure was retained for the year value in the DDD per prescription model. Data for any outlying observations were assessed to ensure that recording errors were not present; however, models were built using all observations to limit any potential bias.

Antimicrobial use data from 2009 were acquired from ESAC-Net $(2,3)$, and rankings performed such that the country with lowest use was assigned a rank of 1 . Comparisons were made using the PrID, DID and DDD per prescription measures. All calculations and analyses were performed using SAS version 9.3 (SAS Institute Inc, USA) for Windows (Microsoft Corporation, USA) and graphs were produced in Excel (Microsoft Corporation, USA).

\section{RESULTS}

Seven ML antimicrobials were used in outpatient antimicrobial therapy by Canadians during the time frame from January 1995 to December 2010. Five macrolide antimicrobials were used (azithromycin, clarithromycin, erythromycin, spiramycin and telithromycin), and the lincosamide group were represented by clindamycin and lincomycin.

Clarithromycin, erythromycin, azithromycin and clindamycin use represented $99.6 \%$ of ML use in Canada (in descending order). 


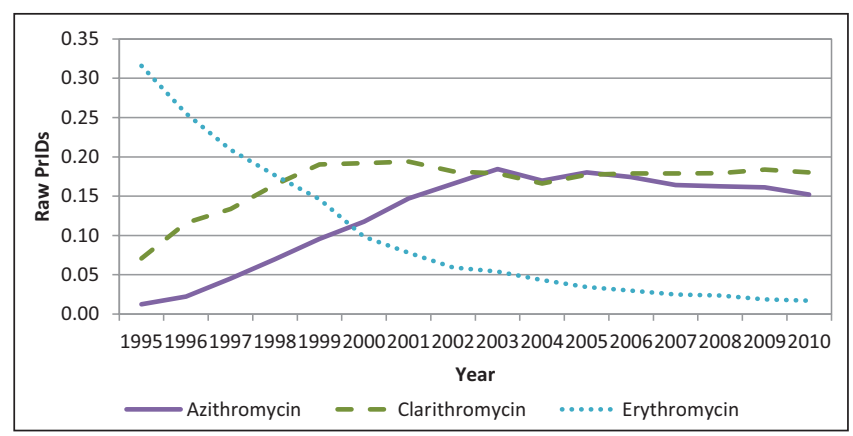

Figure 3) Raw prescriptions per 1000 inhabitant-days (PrIDs) for azithromycin, clarithromycin and erythromycin dispensed on an outpatient basis to Canadians, 1995 to 2010

Lincomycin, spiramycin and telithromycin together accounted for $<0.5 \%$ of total ML prescribing from 2000 to 2010 .

Significant differences among provincial prescribing rates were determined using the mixed modelling strategy $(\mathrm{P}<0.001)$. Similarly, variation among years was determined to be significant at $\mathrm{P}<0.001$. Prescriptions increased overall from 1995 to 2003, followed by a modest decline and plateau from 2004 to 2010 such that rates returned to those observed in 1995 (Figure 1). Prescribing rates were lowest in Quebec and highest in Newfoundland and Labrador over the entire time frame. Table 1 presents the significant $\mathrm{P}$ values for all pairwise combinations of provinces and acts as a legend for Figure 1.

The DDDs per prescription did not vary significantly according to province after accounting for repeated measures. The effect of year was significant at $\mathrm{P}<0.001$, displaying a yearly trend of increasing DDDs per prescription $(\mathrm{P}<0.001)$ (Figure 2$)$.

The dynamics of ML use changed over the time frame examined, with erythromycin use dropping dramatically as the newer products azithromycin and clarithromycin were adopted. Acceptable linear models could not be found to describe these patterns at the provincial level due to the small number of PrIDs, and models at the national level were ill-fitting. Therefore, the raw PrIDs are displayed in Figure 3.

Because Canadian PrIDs varied significantly among the provinces, provincial DID and PrID values were used to compare provincial use with reported rates from European Union (EU) countries (Table 2). For the DIDs, 42 countries or provinces were ranked ( $32 \mathrm{EU}$ countries and 10 Canadian provinces), with number 1 representing the country with the lowest levels of DIDs (Sweden) and number 42 the country with the highest level of DIDs (Greece). All Canadian provinces fell into the lower one-half of the rankings; Manitoba had the highest ranking at 21 of 42, while Newfoundland and Labrador was ranked 41 of 42 . With regard to PrIDs, of 27 reports (17 EU countries and 10 Canadian provinces), British Columbia had the highest ranking at 8 of 27 and Newfoundland again had the lowest at 22 of 27 . Because the linear mixed models determined that there were no significant differences in the DDDs per prescription values among the provinces, the Canada-level DDD per prescription value was used for ranking with 17 reporting EU countries and was ranked 17 of 18 .

\section{DISCUSSION}

Although outpatient prescriptions filled for antimicrobial agents declined by nearly 12\% in Canada from 2000 to 2010 (author's unpublished observations), use of the ML class of antimicrobials in 2010 was approximately equal to use measured in 1995. The individual drugs used within the ML class did change, however. Azithromycin and clarithromycin effectively replaced the use of erythromycin over the 1995 to 2002 time period; erythromycin use dropped by $95 \%$ from 1995 to 2010 , while azithromycin use increased more than 10-fold (1116\%), and clarithromycin use increased by $154 \%$. Significant differences in ML class use exist in PrIDs among the provinces, with high and low rates occurring in Newfoundland and Labrador and Quebec, respectively. These results are similar to those observed for the beta-lactam class of
TABLE 2

Comparison of total macrolide use among Canada and the reporting European Surveillance of Antimicrobial Resistance Network countries according to defined daily doses (DDDs) per 1000 inhabitant-days (DID), prescriptions per 1000 inhabitant-days (PrIDs) and DDD per prescription (Rx) measures in 2009

\begin{tabular}{|c|c|c|c|c|c|c|}
\hline \multirow{2}{*}{$\begin{array}{l}\text { Country/ } \\
\text { province }\end{array}$} & \multicolumn{2}{|c|}{ DID } & \multicolumn{2}{|c|}{ PrID } & \multicolumn{2}{|c|}{ DDD per Rx } \\
\hline & Value & Rank & Value & Rank & Value & Rank \\
\hline Alberta & 4.38 & 35 & 0.42 & 12 & . & . \\
\hline Austria & 3.93 & 31 & 0.60 & 25 & 6.51 & 9 \\
\hline Belgium & 2.96 & 17 & 0.39 & 10 & 7.55 & 14 \\
\hline $\begin{array}{l}\text { British } \\
\text { Columbia }\end{array}$ & 3.74 & 25 & 0.34 & 7 & . & . \\
\hline Bulgaria & 3.20 & 19 & 0.56 & 23 & 5.67 & 5 \\
\hline Canada & . & . & . & . & 9.88 & 17 \\
\hline Croatia & 3.24 & 20 & 0.59 & 24 & 5.52 & 3 \\
\hline Cyprus & 3.98 & 32 & NR & NR & NR & NR \\
\hline Czech Republic ${ }^{\dagger}$ & 3.66 & 23 & 0.49 & 19 & 7.40 & 13 \\
\hline Denmark & 2.25 & 13 & 0.28 & 4 & 8.00 & 16 \\
\hline Estonia & 2.09 & 12 & 0.33 & 5 & 6.41 & 8 \\
\hline Finland & 1.46 & 4 & 0.24 & 3 & 5.98 & 7 \\
\hline France & 4.15 & 33 & $N R$ & NR & $\mathrm{NR}$ & NR \\
\hline Germany & 2.51 & 15 & NR & NR & $N R$ & NR \\
\hline Greece & 11.54 & 42 & 1.09 & 26 & 10.60 & 18 \\
\hline Hungary & 3.00 & 18 & NR & NR & NR & NR \\
\hline Iceland & 1.15 & 3 & NR & NR & NR & NR \\
\hline Ireland $^{\dagger}$ & 3.79 & 26 & 0.49 & 18 & 7.73 & 15 \\
\hline Israel & 1.90 & 9 & NR & NR & NR & NR \\
\hline Italy* & 5.33 & 39 & 1.68 & 27 & 3.18 & 1 \\
\hline Latvia & 0.87 & 2 & NR & NR & NR & NR \\
\hline Lithuania & 1.93 & 11 & 0.33 & 6 & 5.86 & 6 \\
\hline Luxembourg & 3.87 & 28 & NR & NR & NR & NR \\
\hline Malta & 3.89 & 30 & NR & NR & NR & NR \\
\hline Manitoba & 3.63 & 21 & 0.43 & 13 & . & . \\
\hline New Brunswick & 4.62 & 37 & 0.46 & 16 & . & . \\
\hline $\begin{array}{l}\text { Newfoundland } \\
\text { and Labrador }\end{array}$ & 6.53 & 41 & 0.55 & 22 & . & . \\
\hline Norway & 1.68 & 6 & NR & NR & NR & NR \\
\hline Nova Scotia & 4.35 & 34 & 0.44 & 14 & . & . \\
\hline Ontario & 4.51 & 36 & 0.48 & 17 & . & . \\
\hline $\begin{array}{l}\text { Prince Edward } \\
\text { Island }\end{array}$ & 4.95 & 38 & 0.52 & 20 & . & . \\
\hline Poland & 3.88 & 29 & NR & NR & NR & NR \\
\hline Portugal & 3.83 & 27 & 0.53 & 21 & 7.17 & 11 \\
\hline Quebec & 3.74 & 24 & 0.36 & 8 & . & . \\
\hline Romania & 1.84 & 8 & $\mathrm{NR}$ & NR & NR & $\mathrm{NR}$ \\
\hline $\begin{array}{l}\text { Russian } \\
\text { Federation }\end{array}$ & 1.72 & 7 & 0.38 & 9 & 4.51 & 2 \\
\hline Saskatchewan & 3.65 & 22 & 0.44 & 15 & . & . \\
\hline Slovakia & 6.09 & 40 & $\mathrm{NR}$ & NR & NR & $\mathrm{NR}$ \\
\hline Slovenia & 2.33 & 14 & 0.41 & 11 & 5.63 & 4 \\
\hline Spain & 1.90 & 10 & $\mathrm{NR}$ & NR & $N R$ & NR \\
\hline Sweden & 0.63 & 1 & 0.09 & 1 & 7.21 & 12 \\
\hline The Netherlands & 1.46 & 5 & 0.22 & 2 & 6.55 & 10 \\
\hline United Kingdom & 2.51 & 16 & NR & NR & NR & NR \\
\hline
\end{tabular}

Lowest use ranking $=1$. ${ }^{*} 2008$ values; ${ }^{\dagger} 2007$ values. NR Not reported

antimicrobials (7). Although the use in 2010 was similar to that in 1995, year-to-year variation in ML prescribing occurred over the time frame, with peaks in use occurring in 2001 and 2003.

Despite differences in prescription rates among the provinces, the amount of active ingredient dispensed per prescription did not vary 
across the country. A possible trend of increasing strength and/or duration of treatment occurred for ML prescriptions from 2000 to 2010, as indicated by the increases in DDDs per prescription. This increase is likely to reflect a reduction in the proportion of prescriptions dispensed to children versus prescriptions dispensed to adults (author's unpublished observations). However, it should be noted that IMS Health Canada does not collect information on length of time for the prescription. Although they do collect information regarding the age group for which the prescriptions were written, this information was not obtained for the present study.

The use of ML antimicrobials in Canada is higher than the majority of reported use in the ESAC-Net participating countries. However, overall use of antimicrobials in Canada is comparable with these countries. These results suggest that ML antimicrobials are relatively more popular options for prescribers in Canada than in the EU. Although the penicillins are the most often used class of antimicrobials in Canada (1), they are used at a more moderate rate than in reporting EU countries. Therefore, the higher ranking of Canada for ML use is likely to reflect that a portion of penicillin use is 'replaced' by macrolides in Canada. The appropriateness of this 'replacement' may be a question for further research, especially in the context of selection

\section{REFERENCES}

1. Government of Canada. Canadian Integrated Program for Antimicrobial Resistance Surveillance (CIPARS) Human Antimicrobial Use Short Report, 2000-2009. Guelph: Public Health Agency of Canada, 2011.

2. Adriaenssens N, Coenen S, Versporten A, et al. European surveillance of antimicrobial consumption (ESAC): Outpatient antibiotic use in Europe (1997-2009). J Antimicrob Chemother 2011;66(Suppl 6):vi3-vi12.

3. Versporten A, Coenen S, Adriaenssens N, et al. European Surveillance of Antimicrobial Consumption (ESAC):

Outpatient macrolide, lincosamide and streptogramin use in Europe (1997-2009). J Antimicrob Chemother 2011;66(Suppl 6):vi37-vi45.

4. The Canadian Committee on Antibiotic Resistance. The PanCanadian Stakeholder Consultations on Antimicrobial Resistance. 2009. <www.nccid.ca/files/AMR_RAM/Pan_Canadian_AMR_ consultation_2009.pdf> (Accessed August 15, 2012). for antimicrobial resistance, and would require prescription and diagnosis-level data.

We acknowledge that there are limitations to our study, which include the lack of DDD data for the 1995 to 1999 time period, and prescribing information for ML antimicrobials other than azithromycin, clarithromycin and erythromycin between 1995 and 1999. Furthermore, we acknowledge the potential for nonrepresentativeness of measured pharmacies. However, despite missing prescription counts and DDD measurements for 1995 to 1999, the data acquired contained sufficient information to support the linear mixed models described and to detail trends in provincial use over time. Furthermore, the large proportion of pharmacies represented in the dataset $(>64 \%$ of all Canadian outpatient pharmacies in September 2011) and the extensive extrapolation method used by IMS Health Canada supports our belief that these data truly reflect antimicrobial use patterns in Canada $(1,5)$.

DISCLAIMER: This article was prepared using data from IMS Health Canada Inc. The analyses, conclusions, opinions and statements expressed are those of the authors and not those of IMS Health Canada Inc.

5. IMS Health Canada. Unlocking the value of health information: how Canada's healthcare community uses IMS evidence-based intelligence to improve healthcare. 2007. <www.imshealth.com/ims/ Global/Content/Solutions/Solutions\%20by\%20Sector/Providers/ ValueofHealthInformation.pdf> (Accessed April 24, 2012).

6. Statistics Canada. Table 051-0001 - Estimates of population, by age group and sex for July 1, Canada, provinces and territories, annual (persons), 1971 to 2010 (table), CANSIM (database), Using E-STAT (distributor). <www5.statcan.gc.ca/cansim/ a05?lang=eng\&id=0510001 $>$ (Accessed March 21, 2012).

7. Glass-Kastra SK, Finley R, Hutchinson J, Patrick DM, Conly J. Longitudinal surveillance of outpatient $\beta$-lactam antimicrobial use in Canada, 1995 to 2010. Can J Infect Dis Med Microbiol 2014;25:107-112. 


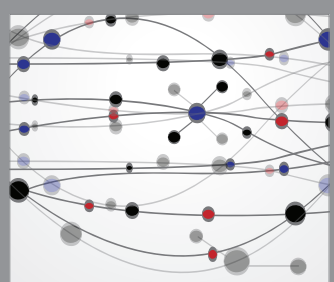

The Scientific World Journal
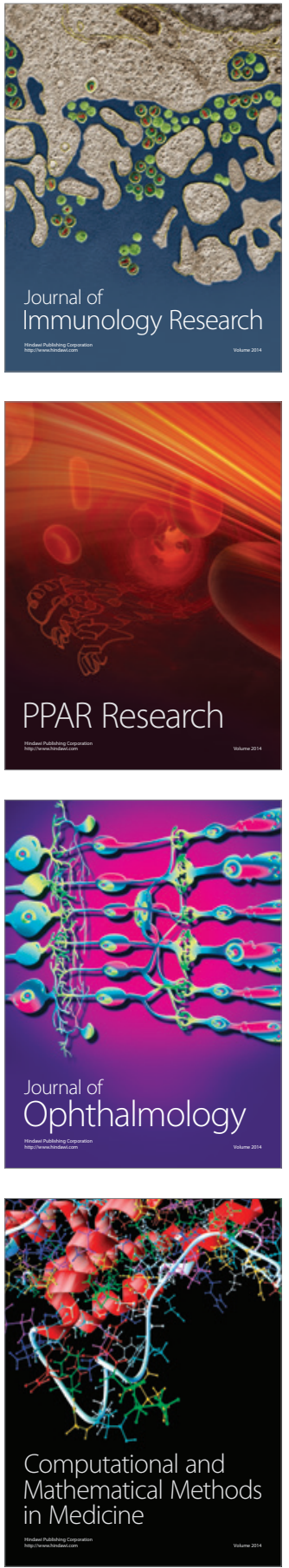

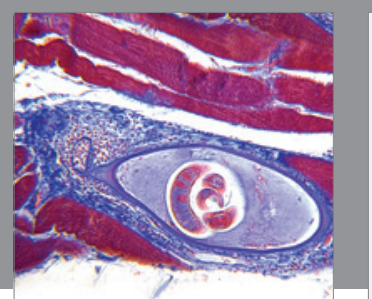

Gastroenterology Research and Practice

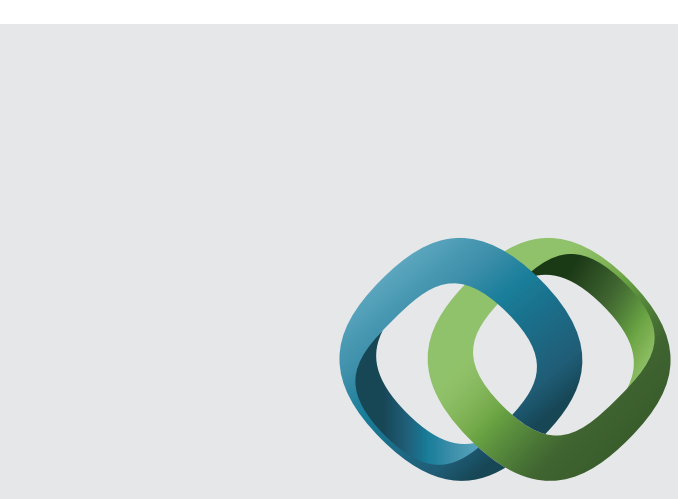

\section{Hindawi}

Submit your manuscripts at

http://www.hindawi.com
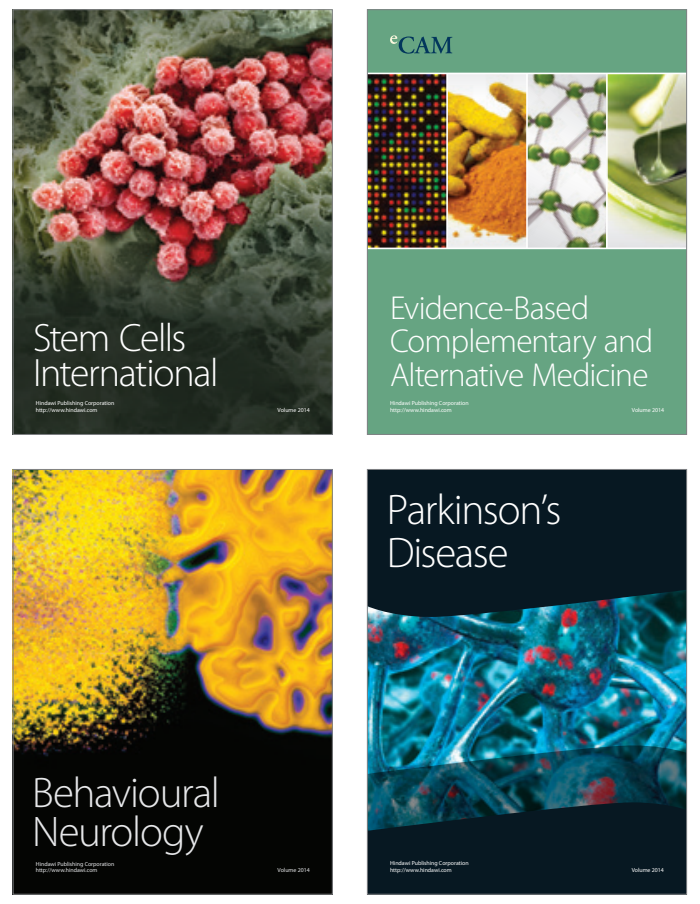
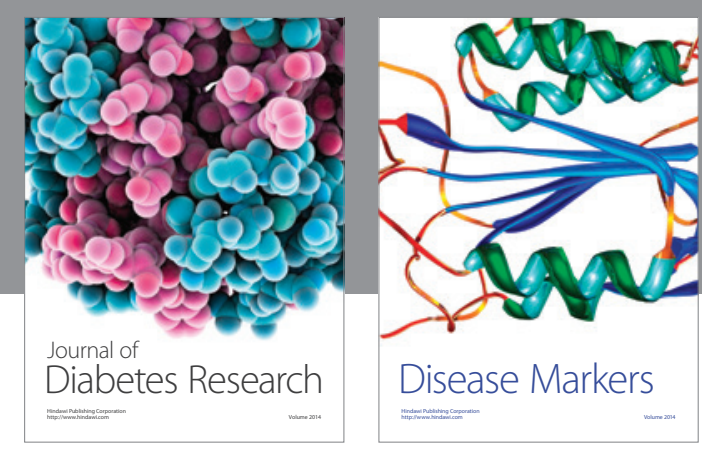

Disease Markers
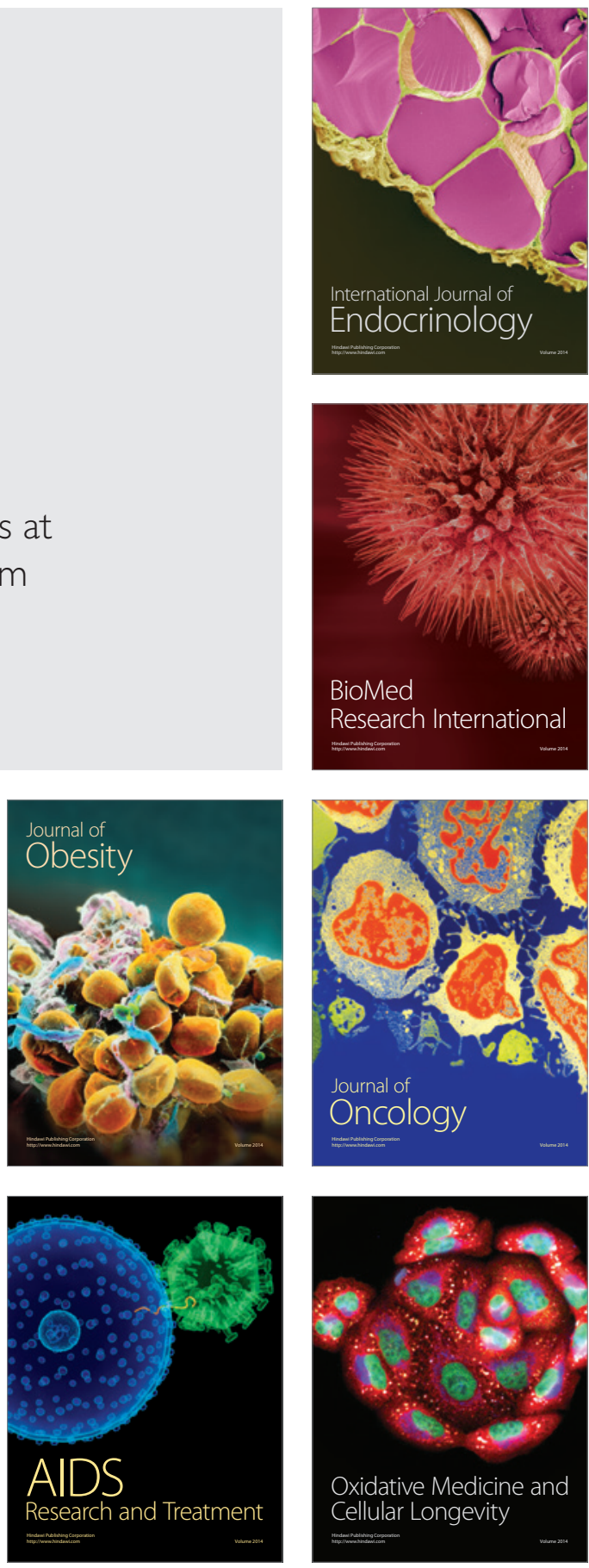